\title{
Preparation and Evaluation of Gastro Retentive Floating Tablets of Atorvastatin Calcium
}

\author{
Florida Sharmin ${ }^{1}$, Md. Abdullah Al Masum ${ }^{1}$, S. M. Ashraful Islam ${ }^{1}$ \\ and Md. Selim Reza ${ }^{2}$ \\ ${ }^{1}$ Department of Pharmacy, University of Asia Pacific, Dhanmondi, Dhaka-1209, Bangladesh \\ ${ }^{2}$ Department of Pharmaceutical Technology, Faculty of Pharmacy, University of Dhaka, Dhaka-1000, \\ Bangladesh
}

\begin{abstract}
This investigation describes the preparation and in vitro evaluation of gastro retentive floating tablets of atorvastatin calcium. Two hydrophilic cellulose derivatives, Methocel K4M and Methocel K15M CR were used in floating tablets as gel forming agents to control drug release. Sodium bicarbonate and citric acid were incorporated as gas generating agents. The tablets prepared by direct compression technique were evaluated by various quality parameters including weight variation, hardness and buoyancy studies. In vitro drug release was determined for eight hours using USP XXII paddle-type dissolution apparatus in $0.1 \mathrm{~N} \mathrm{HCl}$ solution containing $1 \%$ sodium lauryl sulphate. The release mechanisms were explored and explained with zero order, first order, Higuchi and Korsmeyer equations. The release rates, extent and mechanisms, were found to be governed by polymer loading. It was also found that the polymer content significantly affected the mean dissolution time, percentage of drug release, release rate constant and diffusion exponent. Based on the dissolution data and floating time, formulation F-3 containing Methocel K4M and F-9 containing Methocel K15M CR may be considered as the best formulation. So an effective floating tablet of atorvastatin calcium can be prepared by using both the grades of HPMC.
\end{abstract}

Key words: Floating tablets, buoyancy, sustained release, hydrophilic polymer, atorvastatin calcium.

\section{INTRODUCTION}

Most of the orally administered dosage forms have several physiological limitations, such as GI transit time, impaired drug absorption due to incomplete release of drug from the dosage forms and too short residence time of the dosage forms in the absorption region of GI tract. Gastro-retentive systems can remain in the gastric region for several hours and hence can significantly prolong the gastric residence time of drugs. Prolonged gastro retention of the therapeutic moiety may offer numerous advantages: better bioavailability, reduced drug waste and improved solubility of drugs that are less soluble in a high $\mathrm{pH}$ environment of small intestine. ${ }^{1}$ It can also be used for local drug delivery to the stomach and proximal small intestine. ${ }^{2}$ Different approaches

Correspondence to: Md. Selim Reza

Tel: +880-2-9677623; Fax: +880-2-8615583

Email: selim.du@gmail.com

Dhaka Univ. J. Pharm. Sci. 10(2): 79-85, 2011 (December) have been proposed to retain the dosage form in the stomach. Those approaches include preparation of high density dosage form, concomitant administration of drugs or excipients, preparation of bio-adhesive or mucoadhesive dosage form. ${ }^{3-5}$ But the simplest and possibly the most elegant way to improve drug absorption is to hold a drug delivery system on and above the absorption window. Because most absorption windows are located in the proximal small intestine (duodenum), the most effective strategy will be to hold the formulation in the stomach. ${ }^{6}$

When a drug is formulated with gel forming hydrocolloid such as hydroxypropylmethylcellulose (HPMC) and carbon dioxide generating agents like citric acid and sodium hydrogen carbonate it swells in the gastric fluid as it gets contact with the aqueous medium. Formation of carbon dioxide $\left(\mathrm{CO}_{2}\right)$ and entrapment of that gas into the polymeric gel causes swelling of the dosage resulting a bulk density less 
than 1. It then remains buoyant and floats in the gastric fluid that is responsible for prolonged gastric residence time. This floating dosage form is well known as a Hydrodynamically Balanced System (HBS). ${ }^{7}$ It has been suggested that an active material should be formulated in the form of an HBS to enhance bioavailability of those drugs having a dissolution or stability problem in the small intestinal fluid, drugs which are being locally effective in the stomach and drugs with a narrow therapeutic window. ${ }^{8}$

Atorvastatin calcium is a $\mathrm{HMG}-\mathrm{CoA}$ reductase inhibitor used in the treatment of hyperlipidaemia. Oral bioavailability of atorvastatin calcium is less than $12 \%{ }^{9}$ It also undergoes high first pass metabolism. It is absorbed more in the upper part of the GIT. ${ }^{10}$ So oral absorption of atorvastatin can be increased by increasing gastric retention time of the drug.

In this study an initiative was taken to formulate atorvastatin as a floating drug delivery system in order to improve absorption and bioavailability. We used two hydrophilic cellulose derivatives: Methocel K4M and Methocel K15M CR as hydrophilic polymers. Sodium bicarbonate and citric acid were incorporated in the formulation as gas generating agents. Effect of polymer loading upon the floating lag time of the tablets, release rate, mean dissolution time and release mechanism were evaluated with the help of various mathematical models.

\section{MATERIALS AND METHODS}

Materials. Atorvastatin calcium, Methocel K4M and Methocel K15M CR were obtained from Incepta Pharmaceuticals Limited as gift samples. Polyvinylpyrrolidone K-30 and two gas generating agents, citric acid and sodium bicarbonate were collected from ACI Pharmaceuticals Ltd. All other ingredients were of analytical grade and procured from local market.

Preparation of floating tablets of atorvastatin calcium. The active ingredient and other excipients were accurately weighed according to the formulations (Table 1). Particular attention was given to ensure uniform mixing of the components. The mixture was accurately weighed in an electronic balance (Model: AY-200, SHIMADZU Corporation, Japan) for the preparation of each tablet and finally compressed by using a laboratory hydraulic press. Before compression, the surfaces of the die and punch were lubricated with magnesium stearate. All the preparations were stored in airtight containers at room temperature for further study.

Table 1. Composition of different floating tablets of atorvastatin calcium

\begin{tabular}{lcccccccccccc}
\hline Ingredients (in mg) & F-1 & F-2 & F-3 & F-4 & F-5 & F-6 & F-7 & F-8 & F-9 & F-10 & F-11 & F-12 \\
\hline Atorvastatin calcium & 80 & 80 & 80 & 80 & 80 & 80 & 80 & 80 & 80 & 80 & 80 & 80 \\
Methocel K4M & 100 & 120 & 140 & 160 & 180 & 200 & - & - & - & - & - & - \\
Methocel K15M CR & - & - & - & - & - & - & 100 & 120 & 140 & 160 & 180 & 200 \\
PVP K-30 & 40 & 40 & 40 & 40 & 40 & 40 & 40 & 40 & 40 & 40 & 40 & 40 \\
Ludipress & 170 & 150 & 130 & 110 & 90 & 70 & 170 & 150 & 130 & 110 & 90 & 70 \\
Sodium bicarbonate & 60 & 60 & 60 & 60 & 60 & 60 & 60 & 60 & 60 & 60 & 60 & 60 \\
Citric acid & 40 & 40 & 40 & 40 & 40 & 40 & 40 & 40 & 40 & 40 & 40 & 40 \\
Magnesium stearate & 5 & 5 & 5 & 5 & 5 & 5 & 5 & 5 & 5 & 5 & 5 & 5 \\
Purified talc & 5 & 5 & 5 & 5 & 5 & 5 & 5 & 5 & 5 & 5 & 5 & 5 \\
Total weight & 500 & 500 & 500 & 500 & 500 & 500 & 500 & 500 & 500 & 500 & 500 & 500 \\
\hline
\end{tabular}

Evaluation of tablets. The average weights for each brand as well as the percentage deviation from the mean value were calculated by weighing 20 tablets from each batch with a calibrated analytical weighing balance (AY-200, Shimadzu, Japan). The hardness, thickness and diameter of prepared tablets were determined with an Automatic Tablet Hardness Tester (8M, Dr Schleuniger, Switzerland). Twenty tablets of each brand were weighed and subjected to abrasion by employing a Veego friabilator (VFT-2, India) at $25 \mathrm{rev} / \mathrm{min}$ for $4 \mathrm{~min}$. The tablets were then 
weighed and compared with their initial weights and percentage friability was calculated.

Determination of in vitro floating lag time. The in vitro buoyancy was determined by floating lag time and total floating time in a $250 \mathrm{ml}$ beaker containing $0.1 \mathrm{~N} \mathrm{HCl}$ solution ( $\mathrm{pH} 1.2)$ maintained at $37{ }^{\circ} \mathrm{C}$. Their physical state was observed for $24 \mathrm{hr}$. The time required for the tablet to rise to the surface was determined as floating lag time and total duration of time by which dosage form remain buoyant was determined as total floating time. ${ }^{11}$

Determination of swelling index (SI). The swelling index of tablets was determined in $0.1 \mathrm{~N} \mathrm{HCl}$ $(\mathrm{pH} 1.2)$ at $37^{\circ} \mathrm{C}$. The swollen weight of the tablet was determined at predefined time intervals over a period of $5 \mathrm{hr}$. The swelling index (SI) expressed as a percentage was calculated from the following equation. $^{12}$

$\mathrm{SI}=\frac{\text { Weight } \text { of tablet at time }(\mathrm{t})-\text { Initial weight of tablet }}{\text { Initial weight of tablet }} \times 100$

In vitro dissolution studies. The release of atorvastatin calcium from floating tablets was determined by using Dissolution Tester USP XXII (paddle method). The dissolution test was performed using $900 \mathrm{ml} \quad 0.1 \mathrm{~N} \mathrm{HCl}$ solution containing $1 \%$ sodium lauryl sulphate at $37{ }^{\circ} \mathrm{C} \pm 0.5^{\circ} \mathrm{C}$ temperature and rpm was 75 . Aliquots of sample were withdrawn from the dissolution medium after predetermined time interval and equal amount of fresh medium was replaced to maintain the volume constant. The samples were filtered, diluted to a suitable concentration with dissolution medium and absorbances were measured at $245 \mathrm{~nm}$ for atorvastatin calcium by using a UV-1201 UV/Visible spectrophotometer (Shimadzu, Japan). Cumulative percentage drug release was calculated by using an equation obtained from standard curve.

In vitro drug release kinetic studies. The dissolution profiles of all the batches were fitted to zero order, first order, Higuchi and Korsmeyer model to ascertain exact mechanism of drug release from the tablets. ${ }^{13-16}$ To characterize the drug release rate, $\mathrm{T}_{50 \%}$ and $\mathrm{T}_{80 \%}$ were calculated from dissolution data according to the following equations:
$\mathrm{T}_{50 \%}=(0.5 / \mathrm{K})^{1 / \mathrm{n}}$

$\mathrm{T}_{80 \%}=(0.8 / \mathrm{K})^{1 / \mathrm{n}}$

Mean Dissolution Time (MDT) was also calculated by the following equation. ${ }^{17}$

$\mathrm{MDT}=(\mathrm{n} / \mathrm{n}+1) \cdot \mathrm{K}^{-1 / \mathrm{n}}$

\section{RESULTS AND DISCUSSION}

Floating tablets of atorvastatin calcium were prepared by direct compression method. Tablets of all the batch had low tablet weight variation (\% deviation $<3.5$ ), whereas percentage weight loss in the friability test was $\leq 0.5 \%$ in all the batches. Drug content of the tablets in all the batches was in the range of $98-102 \%$. Other physical characteristics of tablets like hardness, diameter and thickness are shown in Table 2. Overall, the tablets were of good quality with regard to crushing strength, friability, weight uniformity and drug content.

Buoyancy lag time and total floating time were determined in $0.1 \mathrm{~N} \mathrm{HCl}$ and the results are shown in Table 3. All formulations had floating lag times below 4 minutes and floated on dissolution medium for more than 6 hours. F-5, F-6, F-10, F-11, F-12 showed good Buoyancy lag time (23 sec, $27 \mathrm{sec}, 32$ $\mathrm{sec}, 27 \mathrm{sec}$ and $23 \mathrm{sec}$ respectively) with more than $20 \mathrm{hr}$ total floating time. Polymer loading was found to have a direct relationship in buoyancy characteristics. Shorter floating lag time and higher total floating time were found in case of higher polymer loading. It might be due to better swelling of the matrix for more water intake by water soluble polymers.

The swelling indexes for all formulation (F-1 to F-12) are shown in table 4. Swelling indexes have a direct relationship on tablet floating. Initially the index was found to rise due to the rapid water intake. This water intake makes the matrix swell and thus reduces the bulk density that is responsible for buoyancy. The total floating time hence, depends on the decrease of bulk density. The formulation having a lower total floating time was found to have a 
Table 2. Physico-chemical parameters of the prepared atorvastatin tablets

\begin{tabular}{cccc}
\hline Formulation & Diameter $(\mathrm{mm})$ & Thickness $(\mathrm{mm})$ & Hardness $\left(\mathrm{Kg} / \mathrm{cm}^{2}\right)$ \\
\hline F-1 & $13.07 \pm 0.0023$ & $2.657 \pm 0.0151$ & $18 \pm 0.104$ \\
F-2 & $13.06 \pm 0.0024$ & $2.667 \pm 0.0258$ & $18 \pm 0.107$ \\
F-3 & $13.07 \pm 0.0023$ & $2.750 \pm 0.0306$ & $21 \pm 0.114$ \\
F-4 & $13.08 \pm 0.0019$ & $2.812 \pm 0.0204$ & $23 \pm 0.105$ \\
F-5 & $13.08 \pm 0.0020$ & $2.817 \pm 0.0258$ & $27 \pm 0.171$ \\
F-6 & $13.07 \pm 0.0022$ & $2.813 \pm 0.0204$ & $27 \pm 0.112$ \\
F-7 & $13.07 \pm 0.0025$ & $2.753 \pm 0.0274$ & $18 \pm 0.102$ \\
F-8 & $13.07 \pm 0.0024$ & $2.825 \pm 0.0274$ & $19 \pm 0.104$ \\
F-9 & $13.07 \pm 0.0017$ & $2.783 \pm 0.0258$ & $22 \pm 0.142$ \\
F-10 & $13.07 \pm 0.0021$ & $2.763 \pm 0.0258$ & $25 \pm 0.201$ \\
F-11 & $13.09 \pm 0.0025$ & $2.790 \pm 0.0248$ & $28 \pm 0.104$ \\
F-12 & $13.07 \pm 0.0019$ & $2.830 \pm 0.0274$ & $28 \pm 0.112$ \\
\hline
\end{tabular}

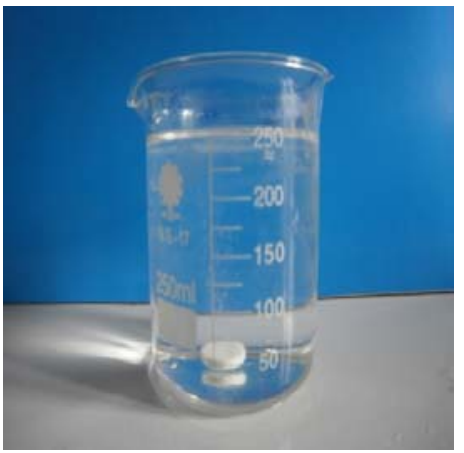

At initial time

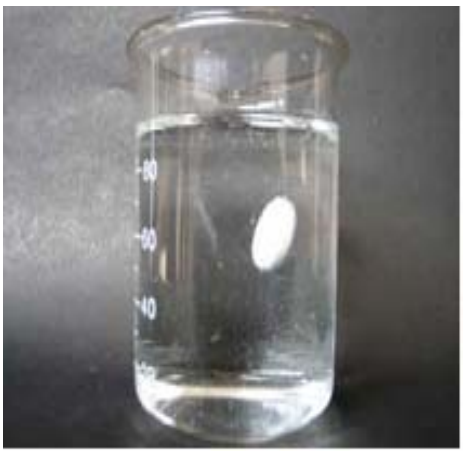

After 25 seconds

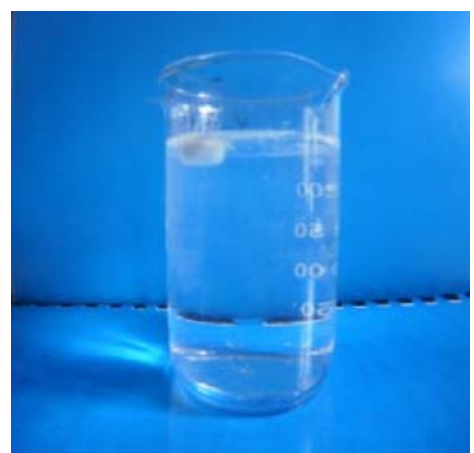

After 27 seconds

Figure 1. In vitro floating behavior of atorvastatin floating tablet.

Table 3. In vitro Buoyancy studies

\begin{tabular}{ccc}
\hline Formulation & $\begin{array}{c}\text { Buoyancy Lag } \\
\text { Time (Sec) }\end{array}$ & $\begin{array}{c}\text { Total Floating } \\
\text { Time (Hour) }\end{array}$ \\
\hline F-1 & 202 & $>6 \mathrm{~h}$ \\
F-2 & 160 & $>6 \mathrm{~h}$ \\
F-3 & 150 & $>12 \mathrm{~h}$ \\
F-4 & 66 & $>18 \mathrm{~h}$ \\
F-5 & 23 & $>20 \mathrm{~h}$ \\
F-6 & 27 & $>24 \mathrm{~h}$ \\
F-7 & 136 & $>6 \mathrm{~h}$ \\
F-8 & 110 & $>8 \mathrm{~h}$ \\
F-9 & 38 & $>14 \mathrm{~h}$ \\
F-10 & 32 & $>20 \mathrm{~h}$ \\
F-11 & 27 & $>24 \mathrm{~h}$ \\
F-12 & 23 & $>24 \mathrm{~h}$ \\
\hline
\end{tabular}

decreasing order of swelling index. On the other hand, an increasing order of swelling index was observed for formulations having higher total floating time. Thus, the findings were found to match the theoretical aspect.

The cumulative percent drug release obtained from formulations F-1 to F-12 are shown in Figures 2-3. All dissolution data are based on the actual drug content of the test tablets as calculated from the assay results. Drug release from different formulation was found to depend on polymer viscosity grade and polymer loading. Formulations F-1, F-2, F-3, F-4, F5 and F-6 containing Methocel K4M showed $88.63 \%, 85.94 \%, 84.93 \%, 72.95 \%, 38.76 \%$ and $35.62 \%$ drug release in 8 hours, respectively. On the other hand formulations F-7, F-8, F-9, F-10, F-11 and F-12 containing Methocel K15 M CR showed $87.67 \%, 84.72 \%, 81.07 \%, 62.00 \%, 40.08 \%$ and $30.95 \%$ drug release respectively.

Methocel K15M CR showed a stronger retardation of the drug release as compared to Methocel K4M in this study. Under identical experimental conditions, the drug diffusivity in viscous water soluble Methocel K15M CR gel is lower than in Methocel K4M. This difference in hindered transport of drug molecules within the two polymers brings out the real cause for the reported higher release retarding ability of Methocel K15M CR compared to Methocel K4M. 
Table 4. Study of swelling indices

\begin{tabular}{cccccc}
\hline Formulation & \multicolumn{5}{c}{ Swelling Index (\%) } \\
\cline { 2 - 6 } & $1 \mathrm{hr}$ & $2 \mathrm{hr}$ & $3 \mathrm{hr}$ & $4 \mathrm{hr}$ & $5 \mathrm{hr}$ \\
\hline F-1 & 30.00 & 22.00 & 14.00 & -0.88 & -5.90 \\
F-2 & 35.00 & 36.10 & 32.08 & 17.70 & 9.00 \\
F-3 & 75.70 & 79.04 & 82.10 & 85.02 & 92.84 \\
F-4 & 82.60 & 85.60 & 86.60 & 96.00 & 99.24 \\
F-5 & 102.44 & 110.08 & 116.14 & 119.70 & 304.62 \\
F-6 & 116.24 & 119.70 & 303.36 & 311.74 & 315.24 \\
F-7 & 31.66 & 24.70 & 18.36 & 15.32 & 8.60 \\
F-8 & 40.52 & 45.96 & 41.68 & 37.06 & 32.60 \\
F-9 & 65.66 & 81.76 & 97.12 & 101.66 & 111.86 \\
F-10 & 89.20 & 97.54 & 104.72 & 119.66 & 302.84 \\
F-11 & 106.90 & 111.52 & 117.86 & 301.06 & 306.48 \\
F-12 & 111.60 & 112.40 & 119.44 & 313.68 & 314.84 \\
\hline
\end{tabular}

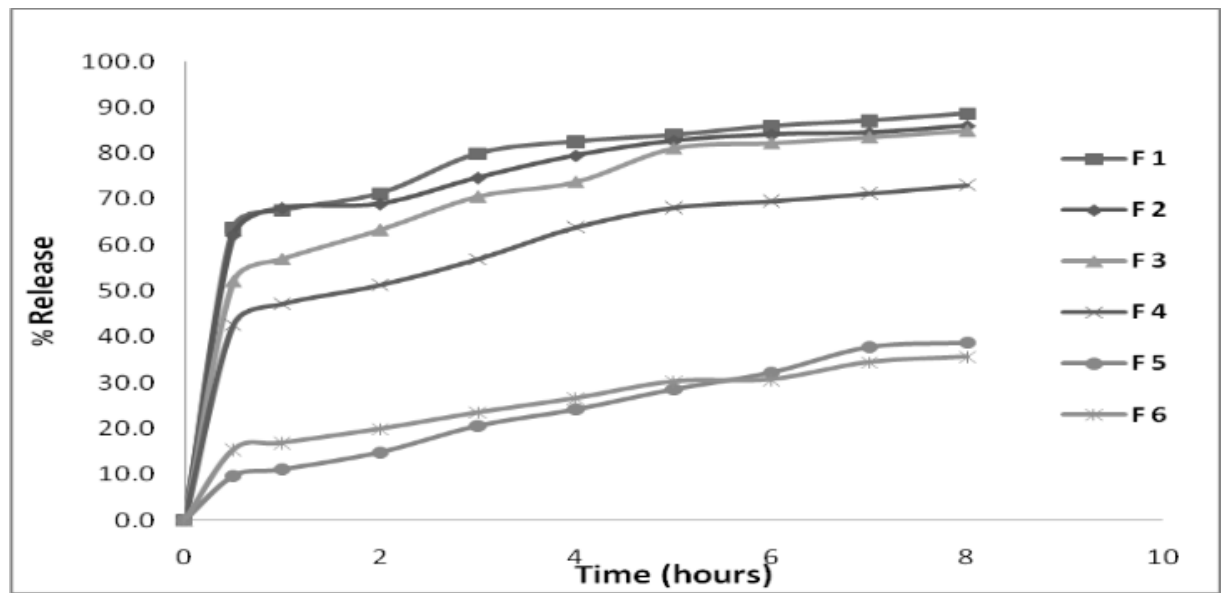

Figure 2. Cumulative percent release profile of atorvastatin from Methocel K4M based floating tablets.

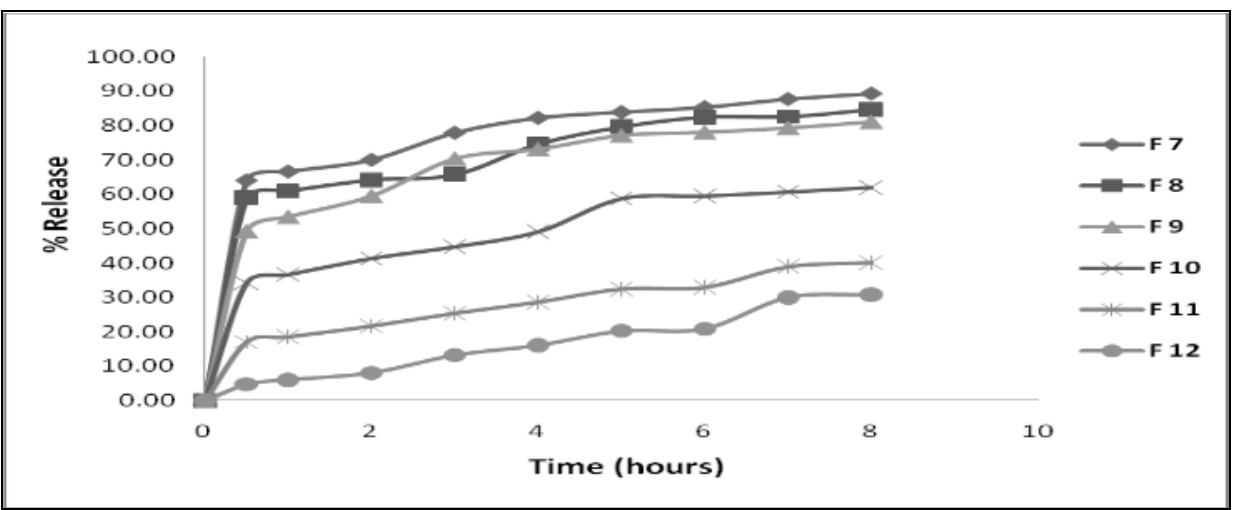

Figure 3. Cumulative percent release of atorvastatin from Methocel K15M CR based floating tablets. 
The MDT values, $\mathrm{T}_{50 \%}$ and $\mathrm{T}_{80 \%}$ of different formulation are summarized in the table 5. All these parameters were found to depend on the type and amount of polymer in the formulation.

Table 5. Successive fractional dissolution time (hr) of atorvastatin calcium

\begin{tabular}{cccc}
\hline Formulation & $\mathrm{T}_{50 \%}$ & $\mathrm{~T}_{80 \%}$ & MDT (hr) \\
\hline F-1 & 0.083 & 3.471 & 2.282 \\
F-2 & 0.087 & 4.390 & 3.020 \\
F-3 & 0.462 & 5.630 & 2.919 \\
F-4 & 1.307 & 12.801 & 6.459 \\
F-5 & 14.124 & 33.724 & 17.876 \\
F-6 & 26.411 & 114.725 & 55.857 \\
F-7 & 0.095 & 3.621 & 2.333 \\
F-8 & 0.231 & 6.178 & 3.680 \\
F-9 & 0.614 & 6.929 & 3.556 \\
F-10 & 3.402 & 25.141 & 12.364 \\
F-11 & 20.092 & 87.278 & 42.494 \\
F-12 & 18.388 & 35.883 & 20.346 \\
\hline
\end{tabular}

The drug release data were fitted to models representing zero order (cumulative amount of drug released vs. time), first order (log percentage of drug unreleased vs. time), Higuchi's (cumulative percentage of drug released vs. square root of time), and Korsmeyer's equation (log cumulative percentage of drug released vs. time) kinetics to know the release mechanisms. The results are summarized in Table 6.

Methocel K4M containing formulations F-1, F-2, F-3 and F-4 were best fitted with Korsmeyer model $\left(\mathrm{R}^{2}\right.$ values are 0.973, 0.960, 0.983 and 0.971, respectively). It seems that these formulations have case II or super case transport II relaxation. So the release is characterized by erosion of the polymeric chain and the matrix. F-5 follows first order release pattern $\left(\mathrm{R}^{2}=0.983\right)$ and F-6 follows Higuchi model $\left(\mathrm{R}^{2}=0.969\right)$. Thus, higher polymeric concentration in the matrix turns the release pattern to diffusion. Similar findings were also found in case of formulations containing Methocel K15M CR. F-7, F8, F-9 and F-10 were best fitted with Korsmeyer model and the $\mathrm{R}^{2}$ values obtained from Korsmeyer model are 0.960, 0.891, 0.975 and 0.935, respectively. F-11 follows Higuchi model $\left(\mathrm{R}^{2}=\right.$ $0.966)$ and F-12 follows Zero order release $\left(\mathrm{R}^{2}=\right.$ 0.979).

Table 6. In vitro release kinetic data for the prepared formulations

\begin{tabular}{ccccccccc}
\hline \multirow{2}{*}{ Formulation } & \multicolumn{2}{c}{ Zero Order } & \multicolumn{2}{c}{ Highuchi } & \multicolumn{2}{c}{ First Order } & \multicolumn{2}{c}{ Korsmeyer } \\
\cline { 2 - 9 } & $\mathrm{K}_{\mathrm{o}}$ & $\mathrm{R}^{2}$ & $\mathrm{~K}_{\mathrm{h}}$ & $\mathrm{R}^{2}$ & $\mathrm{~K}_{1}$ & $\mathrm{R}^{2}$ & $\mathrm{n}$ & $\mathrm{R}^{2}$ \\
\hline F-1 & 6.644 & 0.499 & 24.77 & 0.738 & -0.089 & 0.797 & 0.126 & 0.973 \\
F-2 & 6.409 & 0.495 & 23.87 & 0.731 & -0.080 & 0.772 & 0.120 & 0.960 \\
F-3 & 7.215 & 0.630 & 25.65 & 0.847 & -0.085 & 0.875 & 0.188 & 0.983 \\
F-4 & 6.374 & 0.671 & 22.30 & 0.875 & -0.057 & 0.846 & 0.206 & 0.971 \\
F-5 & 4.513 & 0.968 & 13.90 & 0.978 & -0.025 & 0.983 & 0.504 & 0.965 \\
F-6 & 3.538 & 0.848 & 11.59 & 0.969 & -0.019 & 0.894 & 0.320 & 0.961 \\
F-7 & 6.76 & 0.518 & 24.95 & 0.751 & -0.092 & 0.827 & 0.129 & 0.960 \\
F-8 & 6.708 & 0.571 & 24.12 & 0.786 & -0.079 & 0.833 & 0.143 & 0.891 \\
F-9 & 6.908 & 0.624 & 24.66 & 0.846 & -0.073 & 0.837 & 0.194 & 0.975 \\
F-10 & 5.728 & 0.734 & 19.52 & 0.907 & -0.043 & 0.853 & 0.235 & 0.935 \\
F-11 & 3.952 & 0.860 & 12.84 & 0.966 & -0.022 & 0.909 & 0.320 & 0.946 \\
F-12 & 3.722 & 0.979 & 11.07 & 0.922 & -0.019 & 0.973 & 0.703 & 0.957 \\
\hline
\end{tabular}

\section{CONCLUSION}

Gastro retentive floating tablets of atorvastatin calcium were prepared using two hydrophilic cellulose derivatives, Methocel K4M and Methocel $\mathrm{K} 15 \mathrm{M} \mathrm{CR}$. All the formulations were able to float from 6 to 24 hours with controlling the release rate throughout the time. Methocel K15M CR showed a stronger retardation of the drug release compared with methocel K4M when used in higher quantity. Besides, the most retarding effect was found for 
formulation containing highest concentration of polymers. The release mechanism was mainly diffusion controlled in formulations with higher polymer content. Based on the dissolution data and floating time formulation F-3 containing Methocel K4M and F-9 containing Methocel K15M CR may be considered as the best formulations. So, an effective floating tablet of atorvastatin calcium can be prepared by using both the grades of HPMC. However, in vivo test is required for final selection of formulation.

\section{REFERENCES}

1. Ponchel, G. and Irache, J.M. 1998. Specific and nonspecific bioadhesive particulate system for oral delivery to the gastrointestinal tract. Adv. Drug Del. Rev. 34, 191-219.

2. Deshpande, A. A., Rhodes, C.T., Shah, N.H. and Malick, A.W. 1996. Controlled-release drug delivery systems for prolonged gastric residence: an overview. Drug Dev. Ind. Pharm. 22, 531-539.

3. Singh, B.N. and Kim, K.H. 2000. Floating drug delivery system: An approach to oral controlled drug delivery via gastric retention. J. Control. Release. 63, 235-259.

4. Moes, A.J. 1993. Gastroretentive dosage forms. Crit. Rev. Ther. Drug Carrier Syst. 102, 143-159.

5. Akiyama, Y., Nagahara, N., Nara, E., Kitano, M., Yamamoto, I., Azuma, J. and Ogawa, Y. 1998. Evaluation of oral mucoadhesive microspheres in man on the basis of the pharmacokinetics of flurosemide and riboflavin, compounds with limited gastrointestinal absorption sites. J. Pharm. Pharmacol. 50, 159-166.

6. Chen, J., Blevins, W.E., Park, H. and Park, K. 2000. Gastric retention properties of Super porous hydrogen composites. $J$. Control. Release. 64, 39-51.
7. Uzdemir, N., Ordu, S. and Ozkan, Y. 2000. Studies of floating dosage forms of furosemide: in vitro and in vivo evaluation of bilayer tablet formulations. Drug Dev. Ind. Pharm, 26, 857-866.

8. Jobin, G., Cortot, A. and Godbillon, J. 1985. Investigation of drug absorption from the gastrointestinal tract of man, I: metoprolol in stomach, duodenum, and jejunum. Br. J. Clin. Pharmacol, 19, 97S-105S.

9. http://en.wikipedia.org/wiki/lipitor cited on 25.10.2011.

10. Avachat, Makarand, K., Sharune, and Abhijit, G. Gastric Floating Syatems, US patent No.WO/2002/102415.

11. Dave, B.S., Amin, A.F. and Patel, M. M. 2004. Gastroretentive drug delivery system of ranitidine hydrochloride: formulation and in vitro evaluation. AAPS Pharm. Sci. Tech. 5, E34.

12. Deshpande, A. A., Shah, N.H. and Rhodes, C.T. 1997. Development of a novel controlled-release system for gastric retention. Pharm. Res. 14, 815-819.

13. Khan, G.M. 2001. Controlled Release Oral Dosage Forms: Some recent advances in matrix type drug delivery systems. The Sciences. 1, 350-354.

14. Morkhade, D.M. 2006. Gum copal and gum dammar: novel matrix forming material for sustained drug delivery. Indian J. Pharm. Sci. 68, 53-58.

15. Higuchi, T. 1961. Rate of release of medicaments from ointment bases containing drugs in suspension. J. Pharm. Sci. 50, 874-875.

16. Korsmeyer, R.W., Gurny, R., Docler, E., Buri, P. and Peppas, N.A. 1983. Mechanisms of solute release from porous hydrophilic polymers. Int. J. Pharm. 15, 25-35.

17. Mockel, J.E. and Lippold, B.C. 1993. Zero order release from hydrocolloid matrices. Pharm. Res. 10, 1066-1070. 